\title{
In-situ Diagnostic for Assessing Hall Thruster Wear
}

\author{
Drew M. Ahern ${ }^{1}$, Jason D. Frieman², George Williams ${ }^{3}$, Jonathan A. Mackey ${ }^{4}$, Thomas W. Haag ${ }^{5}$, Wensheng \\ Huang $^{6}$, Hani Kamhawi ${ }^{7}$, and Daniel Herman ${ }^{8}$ \\ NASA Glenn Research Center, Cleveland, OH, USA 44135 \\ Peter Y. Peterson ${ }^{9}$ \\ Vantage Partners, LLC \\ NASA Glenn Research Center, Cleveland, OH, USA 44135 \\ James Gilland ${ }^{10}$ \\ Ohio Aerospace Institute \\ NASA Glenn Research Center, Cleveland, OH, USA 44135 \\ and \\ Richard Hofer ${ }^{11}$ \\ Jet Propulsion Laboratory, California Institute of Technology, Pasadena, CA, USA 91109
}

\begin{abstract}
The design of a new diagnostic to measure the net erosion of Hall thruster surfaces is presented. This diagnostic consists of a pair of optical non-contact profilometer pens mounted to a set of motion stages, which can interrogate the surface features of multiple components of interest including the hollow cathode assembly, magnet front pole covers, and discharge channel. By comparing scans of these surfaces to reference features, estimates of the component erosion rates can be acquired throughout long-duration lifetime tests without venting and removing the thruster from the vacuum facility for external profilometry. This work presents a detailed overview of the diagnostic design including the precision positioning system. In addition, preliminary data are shown which verify diagnostic operation and establish a baseline that will be used to track the erosion of the Hall Effect Rocket with Magnetic Shielding (HERMeS) Technology Demonstration Unit 3 (TDU-3) during an ongoing long-duration wear test.
\end{abstract}

\section{Introduction}

$\mathrm{N}$ ASA continues to evolve a human exploration approach for beyond low-Earth orbit and to do so, where practical, in a manner involving international, academic, and industry partners [1]. NASA publicly presented a reference exploration concept at the Human Exploration and Operations Mission Directorate (HEOMD) Committee of the NASA Advisory Council meeting on March 28, 2017 [2]. This approach is based on an evolutionary human exploration architecture, expanding into the solar system with cis-lunar flight testing and validation of exploration

${ }^{1}$ Research Engineer, Electric Propulsion Systems Branch, drew.ahern@nasa.gov, Member AIAA

${ }^{2}$ Research Engineer, Electric Propulsion Systems Branch, jason.d.frieman@nasa.gov, Member AIAA

${ }^{3}$ Senior Research Engineer, Electric Propulsion Systems Branch, george.j.williams@nasa.gov, Associate Fellow AIAA

${ }^{4}$ Research Engineer, Electric Propulsion Systems Branch, jonathan.a.mackey@nasa.gov, Member AIAA

${ }^{5}$ Senior Research Engineer, Electric Propulsion Systems Branch, thomas.w.haag@nasa.gov, Member AIAA

${ }^{6}$ Research Engineer, Electric Propulsion Systems Branch, wensheng.huang@nasa.gov, Member AIAA

${ }^{7}$ Senior Research Engineer, Electric Propulsion Systems Branch, hani.kamhawi-1@nasa.gov, Associate Fellow AIAA

${ }^{8}$ Senior Research Engineer, Electric Propulsion Systems Branch, daniel.a.herman@nasa.gov, Associate Fellow AIAA

${ }^{9}$ Senior Research Engineer, Electric Propulsion Systems Branch, peter.y.peterson@nasa.gov, Associate Fellow AIAA

${ }^{10}$ Research Team Manager, Electric Propulsion Systems Branch, james.h.gilland@nasa.gov, Associate Fellow AIAA

${ }^{11}$ Senior Engineer, Electric Propulsion Group, richard.r.hofer@nasa.gov, Associate Fellow AIAA 
capabilities before crewed missions beyond the earth-moon system and eventual crewed Mars missions. One of the key objectives is to achieve human exploration of Mars and beyond through the prioritization of those technologies and capabilities best suited for such a mission in accordance with the stepping stone approach to exploration [2].

High-power solar electric propulsion (SEP) is one of those key technologies that has been prioritized because of its significant exploration benefits. Specifically, for missions beyond low Earth orbit, spacecraft size and mass can be dominated by onboard chemical propulsion systems and propellants that may constitute more than 50 percent of spacecraft mass. This impact can be substantially reduced through the utilization of SEP due to its substantially higher specific impulse. Studies performed for NASA's HEOMD and Science Mission Directorate have demonstrated that a 40-kW-class SEP capability can be enabling for both near term and future architectures and science missions [3]. In addition, a high-power, $40 \mathrm{~kW}$-class Hall thruster propulsion system provides significant capability and represents, along with flexible blanket solar array technology, a readily scalable technology with a clear path to much higher power systems.

Accordingly, since 2012, NASA has been developing a 14-kW Hall thruster electric propulsion string that can serve as the building block for realizing a 40-kW-class SEP capability. The 14-kW Hall thruster system development, led by the NASA Glenn Research Center (GRC) and the Jet Propulsion Laboratory (JPL), began with maturation of the Hall Effect Rocket with Magnetic Shielding (HERMeS) and power processing unit. The technology development work has transitioned to Aerojet Rocketdyne via a competitive procurement selection for the Advanced Electric Propulsion System (AEPS) contract. The AEPS contract includes the development, qualification, and multiple flight 14-kW electric propulsion string deliveries. The AEPS SEP string consists of the Hall thruster, power processing unit (including digital control and interface functionality), xenon flow controller, and associated intra-string harnesses. NASA continues to support the AEPS development leveraging in-house expertise, plasma modeling capability, and world-class test facilities. NASA also executes AEPS and mission risk reduction activities to support the AEPS development and mission application.

As part of this effort, NASA has conducted two wear test campaigns to identify erosion phenomena and the accompanying failure modes as well as to validate service-life models for magnetically-shielded thrusters. These campaigns utilized two different technology demonstration unit (TDU) thrusters with similar designs. The first began in 2016 and accumulated approximately $1700 \mathrm{~h}$ of operation using the TDU-1 thruster [4]. The second was performed in 2017 with the TDU-1 and TDU-3 thrusters and consisted of seven short duration ( $200 \mathrm{~h}$ ) segments, each testing a different thruster configuration or operating condition [5]. This test is referred to as the Short Duration Wear Tests (SDWT) throughout this paper.

A new in-situ wear diagnostic was implemented as part of a third wear test (named the TDU-3 Long Duration Wear Test or TDU-3 LDWT), which began in October 2017. This paper presents the detailed design and implementation of this diagnostic as well as preliminary data showing how it might provide additional insight into how erosion changes as a function of operational time and operating condition.

\section{Diagnostic Design Overview}

\section{A. Motivation}

The TDU-3 LDWT is being performed, in part, to demonstrate the diagnostics that will be utilized during the upcoming 23,000 hour test of the AEPS Engineering Design Unit (EDU) thruster [6]. During EDU wear testing, it will be important to understand trends in component wear over time. In prior wear tests of the TDU-1 and TDU-3 thrusters, a benchtop white-light, non-contact profilometer was used to assess the erosion of various thruster components including the cathode keeper and inner and outer front pole covers. The use of a benchtop-model profilometer requires that the wear test be halted and the thruster or components be removed from the facility and exposed to atmosphere in order to obtain erosion measurements. This reduces the overall duty cycle for these extended duration tests and introduces uncertainty related to spalling of deposition and other phenomena resulting from exposing the thruster and cathode to atmosphere as well as handling during removal from the facility.

In order to mitigate the shortcomings associated with the benchtop profilometer, it is desirable to devise an approach for taking scans of the thruster throughout the test operation without opening the chamber. This option is appealing as it enables collection of multiple data points, the thruster remains under vacuum over the duration of the test, and thruster duty cycle is not reduced. This motivated the design of the in-situ diagnostic for use with the HERMeS thruster.

The main objective of the in-situ wear diagnostic is to characterize the time-resolved erosion of thruster surfaces during long duration testing, with a particular focus on the wear of potential life limiting surfaces. As shown in previous HERMeS wear tests, these surfaces are shown in Fig. 1 and include the hollow cathode assembly (HCA), 
including the keeper surface and cathode orifice plate; the inner front pole cover (IFPC); the boron nitride discharge channel edges; and the outer front pole cover (OFPC). Additionally, the in-situ diagnostic can be used to measure changes in the distances between thruster components to assess the ability of the mechanical design to handle thermal cycling and to also identify any changes to these gaps over time.

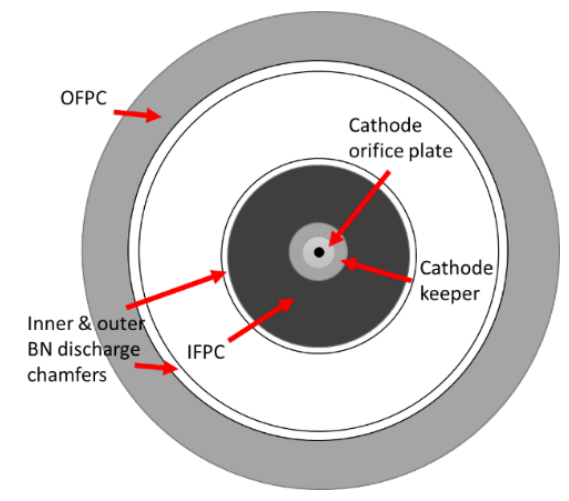

Fig. 1 Features of interest for in-situ diagnostic (not to scale).

\section{B. Measurement Approach}

It is important to note that a reference measurement is needed to determine how much each of these features changes on an absolute scale. The profilometer probes, referred to as "pens," consist of a series of lenses and are each connected to a fiber optic cable that connects to the profilometer instrumentation. The placement of these pens above a thruster feature is not repeatable between scans taken at different test segments (i.e., the distance between the thruster and pens could vary slightly). Therefore, having a feature to use as a reference for a measurement is useful.

For the measurements discussed here, three types of reference measurements are used: a separate known feature of the thruster with an unchanging surface (e.g., a face that does not experience erosion); a previous measurement of the desired feature (e.g., for measuring a diameter, previous measurements of the diameter); and a surface apart from the thruster that does not experience erosion/deposition. For the in-situ diagnostic tests, two identical known graphite features were placed along the outer core of the TDU-3 thruster to function as external references. A CAD model and photo of the final mounting of these features is shown below in Fig. 2. The front face is placed slightly upstream of the outer front pole cover, and the faces behind it are protected from erosion and thus serve as reference surfaces.

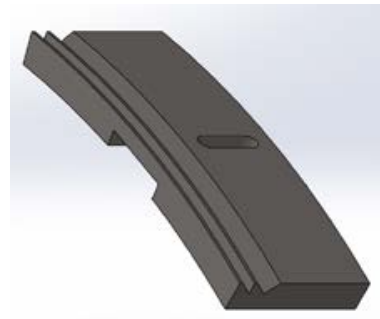

(a)

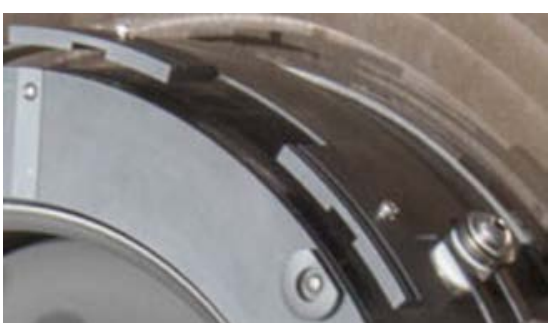

(b)

Fig. 2 (a) CAD model of external reference surface; (b) photo of external reference surfaces mounted on thruster.

Some of the desired measurements on the thruster also require using a pen canted at an angle so as to measure depths of features. For example, a pen oriented normal to the thruster surface is not able to measure a thickness in the direction perpendicular to the plane of the thruster. Therefore, two different pens are used in the in-situ diagnostic design: one that is oriented perpendicular to the thruster surface and one that is canted at $30^{\circ}$ relative to this perpendicular pen. This $30^{\circ}$ pen allows for measurements of features' heights, and it also allows for scanning features hidden from view of the perpendicular pen. Additionally, for the external reference surface discussed above, measuring the faces behind the front face on this external reference requires a profilometer pen that is canted at an angle from the normal direction of the surface face, allowing the light from the pen to reach the surfaces behind the front face. A simple diagram and picture showing the profilometer pen orientation is shown in Fig. 3. 


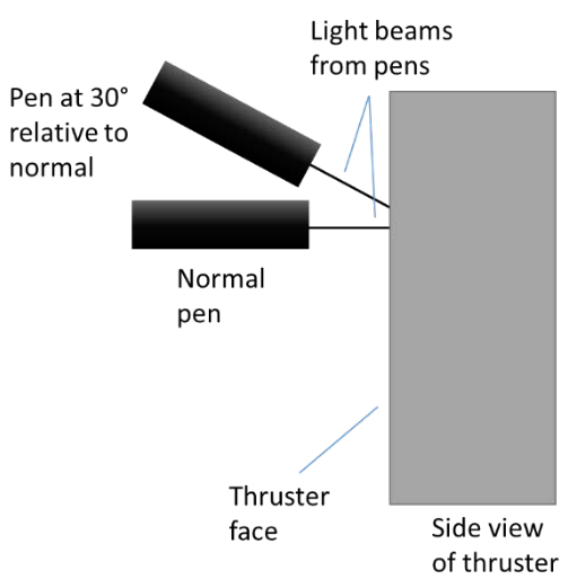

(a)

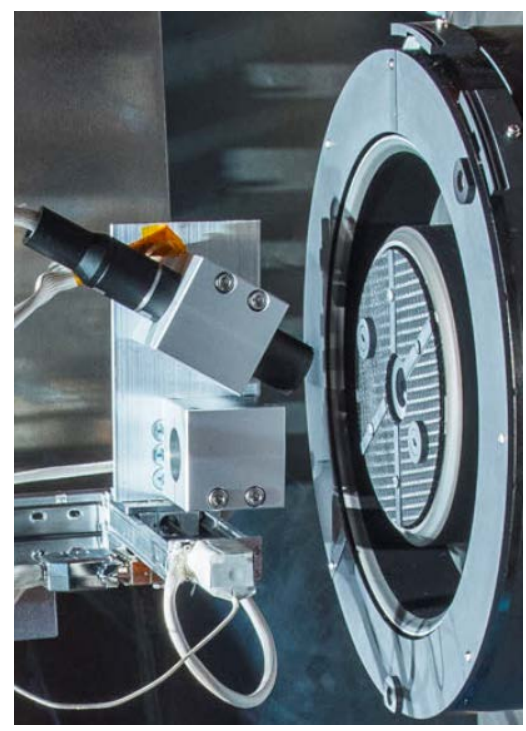

(b)

Fig. 3 (a) Diagram of profilometer pen orientation; (b) actual orientation with Hall thruster (only one pen shown).

In the sections that follow, the specific measurement approach taken for each of the features of interest are discussed along with their respective reference measurements.

\section{Hollow Cathode Assembly}

The two primary components of the HCA to be measured for erosion are the keeper and the cathode orifice plate. In general, primary life-limiters for cathode operation are erosion of the keeper and growth of the orifice diameter [9]. For the HCA, the erosion of the keeper and cathode are assessed because excessive erosion or deposition can lead to anomalous cathode ignition and operation. There are several key measurements of these features, which together show the deposition/erosion of the cathode. These key measurements are illustrated in Fig. 4, with the corresponding measurements and reference features listed in Table 1 . Based on previous external measurements of cathode surfaces, keeper erosion is expected to occur at a rate of approximately $15 \mu \mathrm{m} / \mathrm{kh}[4,5,10]$.

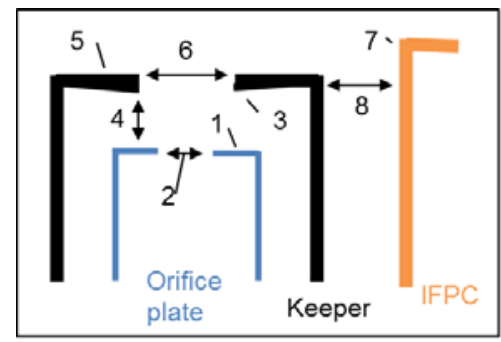

Fig. 4 Cathode measurements.

Table 1 List of cathode measurements.

\begin{tabular}{|c|l|cl|}
\hline$\#$ & \multicolumn{1}{|c|}{ Measurement } & \multicolumn{1}{c|}{ Reference feature } \\
\hline 1 & $\begin{array}{l}\text { Orifice plate surface } \\
\text { erosion }\end{array}$ & $\begin{array}{l}\text { Protected surface on orifice plate that is not affected by erosion/deposition } \\
\text { (see Fig. 9), accessible to pen mounted at 30 relative to normal }\end{array}$ \\
\hline 2 & $\begin{array}{l}\text { Orifice plate orifice } \\
\text { diameter change }\end{array}$ & - & Chamfer and orifice diameter measurements over time \\
\hline 3 & $\begin{array}{l}\text { Deposition thickness } \\
\text { on keeper }\end{array}$ & $\begin{array}{l}\text { Keeper thickness and keeper-to-cathode gap (measurement \#4) measured } \\
\text { over time }\end{array}$ \\
\hline
\end{tabular}




\begin{tabular}{|c|c|c|}
\hline 4 & $\begin{array}{l}\text { Gap between keeper } \\
\text { and orifice plate }\end{array}$ & $\begin{array}{l}\text { - Keeper thickness (measurement \#3) and keeper-to-cathode gap measured } \\
\text { over time }\end{array}$ \\
\hline 5 & Keeper surface erosion & $\begin{array}{ll}\text { - } & \text { External reference surface } \\
\text { - } & \text { Protected surface on orifice plate (same as that mentioned in \#1) }\end{array}$ \\
\hline 6 & $\begin{array}{l}\text { Keeper orifice diameter } \\
\text { erosion }\end{array}$ & $\begin{array}{ll} & \text { Keeper orifice diameter measured over time } \\
\text { - } & \text { External reference surface }\end{array}$ \\
\hline 7 & $\begin{array}{l}\text { IFPC inner bore } \\
\text { erosion }\end{array}$ & $\begin{array}{ll} & \text { Protected surface on bore that is not affected by erosion/deposition }\end{array}$ \\
\hline 8 & Keeper to IFPC gap & $\begin{array}{ll}- & \text { Keeper to IFPC gap measured over time } \\
\text { - } & \text { Measurements of keeper and bore diameters over time }\end{array}$ \\
\hline
\end{tabular}

\section{Inner Front Pole Cover}

The most recent segment of the TDU-3 LDWT was conducted with a carbon-carbon IFPC to replicate the EDU thruster design. In addition, bushings were incorporated on the surface of the IFPC to simulate the EDU design, and graphite strips were mounted to the IFPC to allow for direct comparison between carbon-carbon and graphite erosion. The key measurements of interest of the IFPC are shown in Fig. 5, with the numbered measurements and corresponding reference features listed in Table 2. Erosion is expected to be highest at the IFPC compared to other surfaces, occurring at rates of 10-100 $\mu \mathrm{m} / \mathrm{kh}$, depending on thruster operating condition $[4,5,10]$.

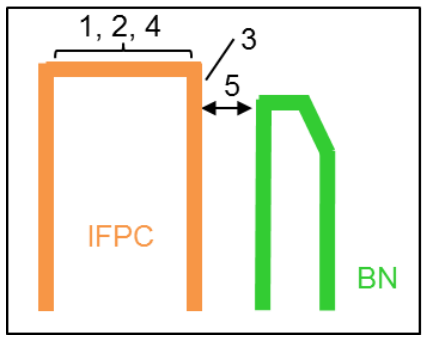

Fig. 5 IFPC measurements.

Table 2 List of IFPC measurements.

\begin{tabular}{|c|c|c|}
\hline$\#$ & Measurement & Reference feature \\
\hline 1 & IFPC erosion: surface & $\begin{array}{ll}- & \text { OFPC surface } \\
- & \text { External reference surface } \\
\text { - } & \text { Correlation of IFPC thickness with erosion depth }\end{array}$ \\
\hline 2 & IFPC erosion: bushing & $\begin{array}{l}\text { - IFPC surface (for only the } 30^{\circ} \text { canted profilometer pen) } \\
\text { - } \quad \text { Correlation of bushing height with erosion depth } \\
\text { - }\end{array}$ \\
\hline 3 & IFPC erosion: side wall & $\begin{array}{ll}\text { - } & \text { IFPC thickness over time } \\
\text { - } & \text { Correlation of IFPC thickness with erosion depth } \\
\text { External reference surface }\end{array}$ \\
\hline 4 & $\begin{array}{l}\text { Graphite vs. C-C erosion } \\
\text { (utilizing graphite strips } \\
\text { in C-C IFPC) }\end{array}$ & $\begin{array}{ll}\text { - } & \text { OFPC surface } \\
\text { - } & \text { External reference surface } \\
\text { - } & \text { Relative change of each surface with time }\end{array}$ \\
\hline 5 & IFPC to channel gap & - IFPC to channel gap measured over time \\
\hline
\end{tabular}

\section{Outer Front Pole Cover and Boron Nitride Channel}

The OFPC was made of graphite and also included bushings to simulate the EDU design. The key OFPC measurements of interest are shown in Fig. 6, with the numbered measurements and corresponding reference features listed in Table 3. The OFPC is expected to have erosion rates of 5-65 $\mu \mathrm{m} / \mathrm{kh}$, depending on thruster operating condition $[4,5,10]$. 


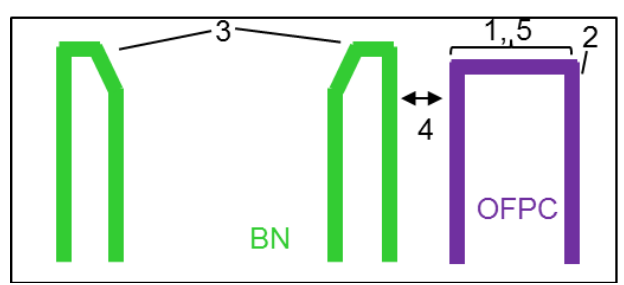

Fig. 6 OFPC measurements.

Table 3 List of OFPC measurements.

\begin{tabular}{|c|c|c|}
\hline$\#$ & Measurement & Reference feature \\
\hline 1 & OFPC erosion: surface & $\begin{array}{ll}\cdot & \text { External reference surface } \\
\text { - } & \text { Correlation of OFPC thickness with erosion depth }\end{array}$ \\
\hline 2 & OFPC thickness: outer walls & $\begin{array}{ll}\cdot & \text { External reference surface } \\
\text { - } & \text { Outer wall thickness measurements over time }\end{array}$ \\
\hline 3 & BN deposition or erosion & $\begin{array}{ll} & \text { External reference surface } \\
\text { - } & \text { BN deposition/erosion measurements over time }\end{array}$ \\
\hline 4 & OFPC to channel gap & $\begin{array}{ll}\text { - } & \text { Gap measurements over time } \\
\text { - } & \text { Reference surface to OFPC gap } \\
\text { IFPC to channel gap }\end{array}$ \\
\hline 5 & OFPC bushing & $\begin{array}{ll}\cdot & \text { External reference surface } \\
\text { - } & \text { OFPC bushing measurements over time } \\
& \text { Correlation of bushing height with erosion depth } \\
\end{array}$ \\
\hline
\end{tabular}

\section{Resolution of Surface Erosion}

As previously mentioned, the expected wear rates of the various surfaces depend on the operating conditions of the thruster, e.g., the discharge voltage, discharge current, and magnetic field strength. Specifically, it has been found that a discharge voltage of $600 \mathrm{~V}$ results in lower erosion rates than a discharge voltage of $300 \mathrm{~V}[5,7,10]$. The time needed to observe surface erosion with the in-situ diagnostic is lower if there is a higher erosion rate. The minimum amount of erosion needed to resolve a measureable change is estimated at $10 \mu \mathrm{m}$ for the higher resolution pen and $15+\mu \mathrm{m}$ for the lower resolution pen.

\section{Design}

\section{Requirements}

In the design of this diagnostic, a main requirement was that it not interfere with thruster operation or existing test apparatus. Specifically, the diagnostic shall not be capable of contacting or have deleterious effects on the thruster or test stand. This encompasses the possibility of anomalous diagnostic motion, including seizure due to diagnostic failure or loss of power. Additionally, in the event of power/communications failure, the diagnostic cannot remain in front of the thruster. If the diagnostic were to get stuck in front of the thruster, it would prevent the thruster from being turned on and would require opening the vacuum chamber to correct. The in-situ diagnostic has to collect data with the thruster off, and when it is not in use, it must remain protected from the thruster plume. This ensures that the profilometers are not damaged by the plasma and also that no backsputtered material from the facility deposits on them. Furthermore, data collection has to occur within a 1-2 day timeframe. Otherwise, measurements would negatively impact the duty cycle of long duration testing.

\section{Profilometer Pens}

The measurement system is a vacuum-rated version of the benchtop-model profilometer used in previous tests [4, 5]. It consists of a pair of white-light non-contact profilometer optical pens. The first pen is oriented normal to the Hall thruster exit plane and has a $3 \mathrm{~mm}$ depth of field (DOF) and a resolution estimated at approximately $5 \mu \mathrm{m}$. This pen is used to scan surfaces oriented parallel to the thruster exit plane located within its DOF. The second pen is oriented at an angle of $30^{\circ}$ relative to the normal of the Hall thruster exit plane. This pen has a $24 \mathrm{~mm}$ DOF and a 15 $\mu \mathrm{m}$ resolution, as measuring a depth change in perpendicular surfaces requires a larger focusing range to resolve the faces. Orienting the pen at this angle allows for height measurements of features in the direction perpendicular to the 
exit plane of the thruster. In addition to taking measurements of surface features, this pen is also used to scan the recessed cathode keeper and orifice plate as well as the vertical and chamfered faces of the discharge channel and bushings attached to both pole covers. It should also be emphasized that the resolution values provided here for both pens are current estimates for the diagnostic, and these values will be refined as measurements are taken and analyzed.

\section{Design Overview}

The in-situ diagnostic is shown in Fig. 7. It consists of a long boom arm that rests horizontally below the thruster and rotates to the position shown to scan the thruster. Gross movement of the boom arm is accomplished with a directdrive rotary motion stage, which is mounted on the downstream surfaces of the thrust stand frame and rotates in the Hall thruster azimuthal direction. One end of the boom arm consists of the profilometer pen setup, and the other end has a counterweight to balance the arm. The use of a direct-drive rotary motion stage provides the diagnostic with a built-in gravity-driven safety feature that can be activated at any time by removing power from the gross motion system; when activated, this safety feature returns the measurement system to its rest location. In the event that this feature is activated, a fall arrestor composed of a pad of Viton attached to a rigid structure is mounted in order to provide damping and lessen the loads on the measurement system. When not in use, the measurement system rests in a box (called the "doghouse") made of protective panels and located approximately $1.25 \mathrm{~m}$ below and $1.25 \mathrm{~m}$ radially outward from the thruster centerline. These panels protect the measurement system by shielding it from both plasma erosion and deposition of backsputtered material from the facility. Two profilometer pens, as discussed in Section II.C.2, are mounted in a custom pen holder. The pens are mounted on a three-axis precision motion system. A fiber optic light and a camera have been placed on the boom arm to provide real-time video of the location of the optical pens relative to the thruster. Additionally, external reference surfaces, as discussed in Section II.B, have been mounted on the Hall thruster and are scanned as part of the data acquisition process. 


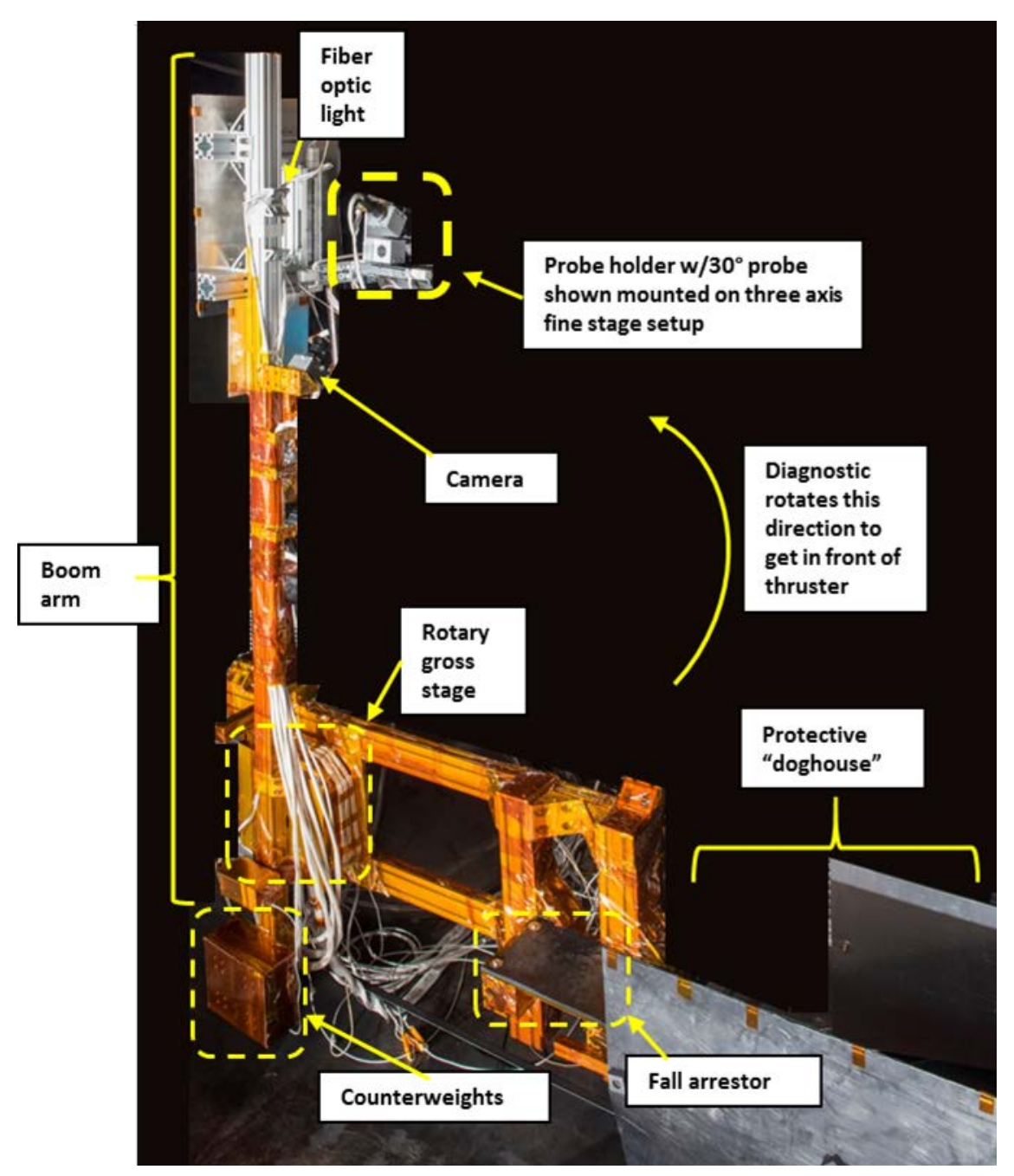

Fig. 7 In-situ wear diagnostic in chamber (thruster not shown).

\section{Preliminary Data}

\section{A. Tabletop Measurements with $3 \mathrm{~mm}$ DOF and $24 \mathrm{~mm}$ DOF Pens}

Prior to the initiation of the wear test, data were collected with the thruster on the benchtop profilometer. The insitu profilometer pen holder replaced the nominal tabletop profilometer pen holder, and both $3 \mathrm{~mm}$ and $24 \mathrm{~mm}$ DOF pens were installed identically to the in-situ configuration. A series of profilometer measurements were made to provide guidance on scan speeds, pen-to-pen relative resolution, and sample size for wear rate assessment. In addition, the use of the tabletop configuration provided a baseline against which to assess the impact of vibrations present in either the pens, vacuum facility, or the thruster during in-situ measurements.

Fig. 8 compares profiles of the keeper downstream surface taken with each pen. Note that the large curvature shown in Fig. 8 resulted from manufacturing or polishing of the keeper and not from erosion during operation. Each profile captures the $15 \mu \mathrm{m}$ steps (circled) between the eroded and previous masked regions of the keeper despite the lower resolution of the $24 \mathrm{~mm}$ DOF pen. Slight differences in the keeper orifice diameter reflect the need to anchor the measurement to a known radial location (i.e., the profile scans of the diameters were not over the exact same location but differed by a very small amount resulting in variations in measured diameter - anchoring the scans to a known location would eliminate this issue). Fig. 9 shows the geometry of the cathode-to-keeper gap as measured by the $24 \mathrm{~mm}$ DOF pen. Note that the keeper orifice wall is shown as an angled line corresponding to the angle of the pen. Horizontal surfaces are shown without distortion and gaps must be calculated by correcting for the pen angle (as indicated by the dotted line showing the cathode-to-keeper gap relative to the keeper thickness). Of particular note is the small region of cathode orifice plate shielded by the keeper from downstream fluxes. This surface serves as a 
reference for changes in the rest of the orifice plate, the gap, and the keeper thickness. This surface is functionally similar to the protected surface on the outer edge of the external reference surface, and, if the two are shown not to move axially due to thermal effects, they can provide an inner to outer absolute reference for the rest of the in-situ measurements.

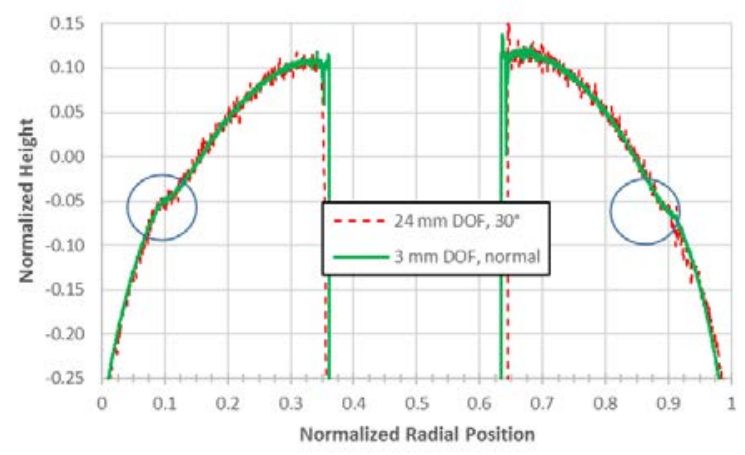

Fig. 8 Tabletop scans of the keeper with both $3 \mathrm{~mm}$ and $24 \mathrm{~mm}$ DOF pens. Domed aspect of keeper is exaggerated here from scaling.

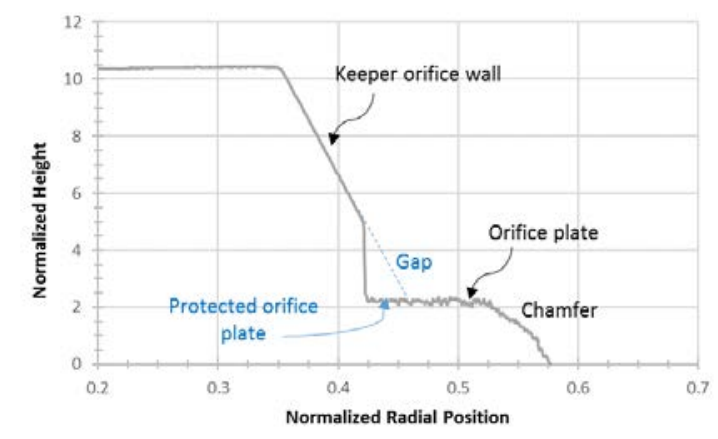

Fig. 9 Tabletop scan of cathode-keeper gap region (only the $24 \mathrm{~mm}$ DOF pen at $30^{\circ}$ was used).

One objective of these tests was to determine the correlation between the two pens. Specifically, the $3 \mathrm{~mm}$ DOF pen has a higher resolution than the $24 \mathrm{~mm}$ DOF pen. By performing a scan of the same area with both pens, the two sets of results were compared, resulting in a correction for the $24 \mathrm{~mm}$ DOF pen. This correction can then be applied to measurements such as IFPC wall thicknesses, which are measured in the perpendicular direction to the exit plane of the thruster. Fig. 10 compares radial profiles of the IFPC taken with each of the pens. The dark line through the center of the data represents a moving average fit to the $3 \mathrm{~mm}$ DOF data. The $24 \mathrm{~mm}$ DOF raw data is not shown here, as it requires significantly more smoothing to recover the same shape. That said, both pens appear to capture the same fabrication-induced features of the pole cover including the large curvatures at the inner and outer edges and the wavy surface. This facilitates the correlation of the two pens referred to in Table 2. Because of the higher resolution and correspondingly higher scan speeds of the $3 \mathrm{~mm}$ DOF pen, its use in the in-situ characterization of the surface is preferred. 


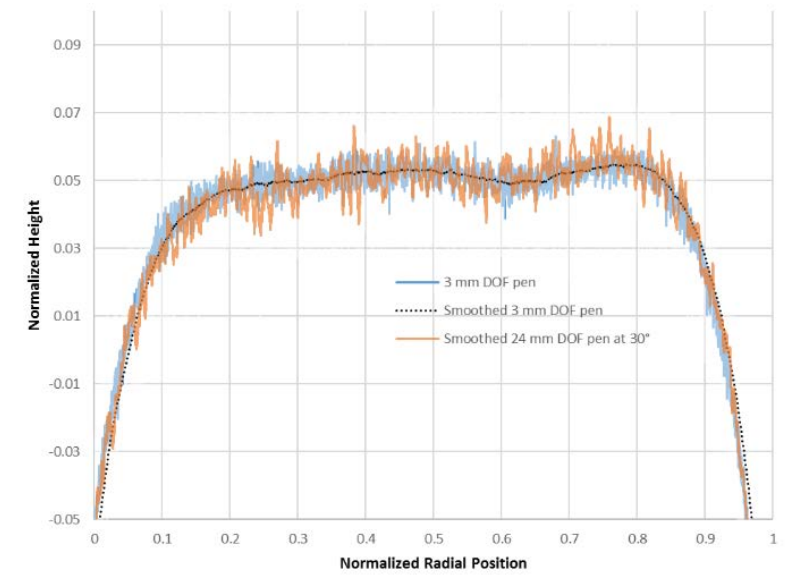

Fig. 10 Comparison of profiles of the inner front pole cover taken with the two optical pens.

From tabletop measurements, it was determined that the in-situ diagnostic should be capable of resolving changes in the keeper and IFPC on the order of 5 to $10 \mu \mathrm{m}$ depending on the pen used and pending the impact of vibrations. For a $600 \mathrm{~V}$ discharge voltage operating point, the first detectable erosion on the IFPC is expected to be $425 \mathrm{~h}$ into a long duration test. Both keeper and IFPC changes will be captured primarily as deviations from the profiles shown above. IFPC erosion rate varies as a function of radius, as shown by references $[4,5,7,10]$. Erosion across the entire IFPC (as opposed to erosion at certain points) should be detected no later than $1500 \mathrm{~h}$ into the test. Erosion across the face of the IFPC will be referenced to either the external reference surface or other surfaces such as the OFPC. It is unclear if erosion will be detected on the keeper earlier than $1500 \mathrm{~h}$.

\section{B. Preliminary Baseline In-Chamber Measurements}

Baseline measurements of the thruster were taken at atmospheric conditions and at vacuum. These scans were taken to determine three things: whether the diagnostic can measure known gaps, whether vibrations from the vacuum pumps cause noise in the data, and how or if the thruster moves during chamber pump down. Additionally, these scans were taken to serve as a baseline against which to compare scans taken later after the thruster has been operating for a given amount of time.

The baseline scans for both atmosphere and vacuum are shown below in Fig. 11. These plots are all segments of a large radial profile scan taken across the face of the thruster, passing through the approximate 12:00 position of the thruster. Overall, the gaps between the thruster components were captured by the scans. Regarding noise, the scans taken at vacuum had similar noise as the scans at atmosphere, indicating that vibrations from the vacuum pumps did not affect the data. The discrepancies between the two sets of scans were the BN discharge channel locations shown in Fig. 11(c) and (d), as it appears that the BN channel shifted slightly during pump down. However, it was found that the rotary gross stage angle may have differed by a small amount $\left(<0.01^{\circ}\right.$ difference) between the atmosphere and vacuum scans, causing the radial scans to be at slightly different positions. Therefore, it cannot be said with certainty that the BN discharge channel shifted slightly or whether the measurements were taken at slightly different locations. To determine the cause of this discrepancy, area scans would be taken, which would allow for better alignment of the measurement areas. These area scans were omitted here due to some issues moving the linear stages but will be incorporated in future scanning. 


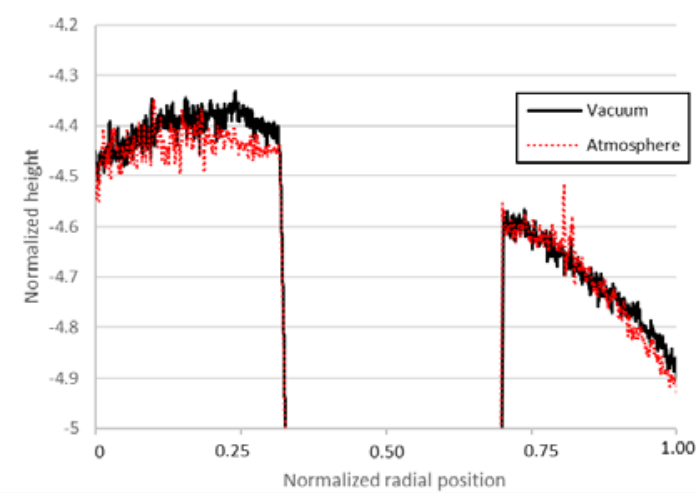

(a)

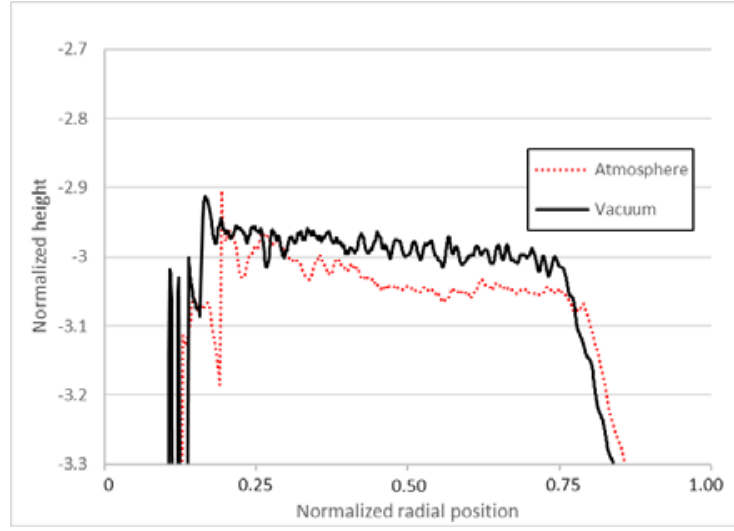

(c)

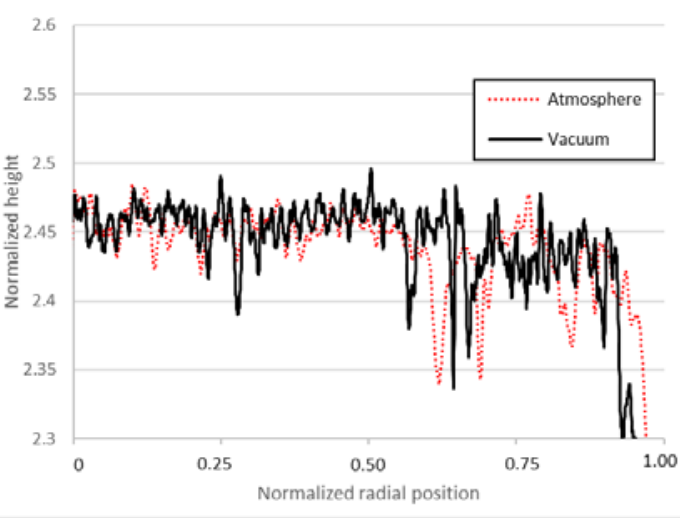

(b)

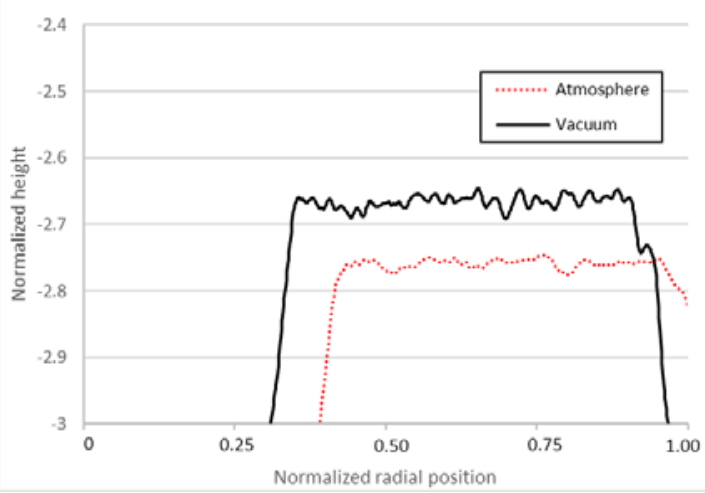

(d)

Fig. 11 In-situ profile scans at vacuum and atmosphere of (a) keeper, (b) portion of IFPC surface, (c) BN discharge channel near IFPC, and (d) BN discharge channel near OFPC.

\section{Conclusions}

An in-situ diagnostic used to measure erosion during long duration Hall thruster testing was developed. It consists of a profilometer setup mounted to a boom arm that, between test segments when the thruster is off, swings in front of the thruster to conduct scans. This diagnostic incorporates profilometer measurements, which have previously been used to scan thruster surfaces, however it has the unique benefit of not needing to open the vacuum chamber to conduct the scans. Requirements of the design have been met, and baseline scans using the in-situ diagnostic have been completed, which have demonstrated the functionality of this device. After several hundred hours of thruster firing, the thruster surfaces will be scanned again, and erosion of the features of interest will be determined.

\section{Acknowledgments}

The authors would like to thank the Space Technology Mission Directorate through the Solar Electric Propulsion Technology Demonstration Mission Project for funding the development of this diagnostic as well as for providing funding for the development of the HERMeS Hall thrusters. The authors would also like to thank Kevin Blake, Matt Daugherty, Josh Gibson, Roland Gregg, Evelyn Hill, George Jacynycz, Chad Joppeck, Jim Szelagowski, Taylor Varouh, Dave Yendriga, Jim Zakany, and all of the engineers and technicians of the Space Environment Test Branch for the setup of the experiment, for fabrication of various components, and for operation of the vacuum facility. Additionally, the authors would like to thank Dave Jacobson of GRC for his technical support and guidance throughout this project. 


\section{References}

[1] Congress, National Aeronautics and Space Administration Transition Authorization Act of 2017.

[2] Gerstenmaier, W., "Progress in Defining the Deep Space Gateway and Transport Plan," NASA Advisory Council Human Exploration and Operations Committee Meeting, 2017.

[3] Smith, B. K., Nazario, M. L., and Cunningham, C. C., "Solar Electric Propulsion Vehicle Demonstration to Support Future Space Exploration Missions", Space Propulsion 2012, Bordeaux France, 2012.

[4] Williams, G., Gilland, J. H., Peterson, P. Y., Kamhawi, H., Huang, W., Swiatek, M., Joppeck, C., Yim, J., and Haag, T. W., "2000-hour Wear-Testing of the HERMeS Thruster," 52nd AIAA/SAE/ASEE Joint Propulsion Conference, AIAA Paper 2016-5025, Salt Lake City, UT, 2016.

[5] Williams, G. J., Kamhawi, H., Choi, M., Haag, T., Huang, W., Herman, D. A., Gilland, J. H., and Peterson, P. Y., “Wear Trends of the HERMeS Thruster as a Function of Throttle Point," $35^{\text {th }}$ International Electric Propulsion Conference, IEPC Paper 2017-207, Electric Rocket Propulsion Society, Fairview Park, OH, 2017.

[6] Herman, D. A., Tofil, T., Santiago, W., Kamhawi, H., Polk, J. E., Snyder, J. S., Hofer, R. R., Picha, F., Jackson, J., and Allen, M., "Overview of the Development and Mission Application of the Advanced Electric Propulsion System (AEPS)," 35 th International Electric Propulsion Conference, IEPC Paper 2017-284, Electric Rocket Propulsion Society, Fairview Park, OH, 2017.

[7] Williams, G. J., Choi, M., Kamhawi, H., Huang, W., Herman, D. A., Gilland, J. H., and Urban, P. J., "Assessment of HERMeS Wear Trends via Optical Emission Spectroscopy," 65 ${ }^{\text {th }}$ Joint Army-Navy-NASA-Air Force Propulsion Meeting, Long Beach, CA, 2018.

[8] Peterson, P. Y., Frieman, J. F., Kamhawi, H., Williams, G., Herman, D., Gilland, J., and Hofer, R., "NASA HERMeS Hall Thruster Long Duration Wear Test," 65 th Joint Army-Navy-NASA-Air Force Propulsion Meeting, Long Beach, CA, 2018.

[9] Herman, D. A. and Gallimore, A. D., "Near Discharge Cathode Assembly Plasma Potential Measurements in a 30-cm NSTAR-type Ion Engine amidst Beam Extraction," 40 ${ }^{\text {th }}$ AIAA/ASME/SAE/ASEE Joint Propulsion Conference and Exhibit, AIAA Paper 2004-3958, 2004.

[10] Frieman, J. D., Kamhawi, H., Williams, G., Herman, D., Peterson, P. Y., Gilland, J., and Hofer, R., "Long Duration Wear Test of the NASA HERMeS Hall Thruster," 54 ${ }^{\text {th }}$ AIAA/SAE/ASEE Joint Propulsion Conference, Cincinatti, OH, 2018. 